\title{
New High Capacity Getter for Vacuum- Insulated Mobile Liquid Hydrogen Storage Systems
}

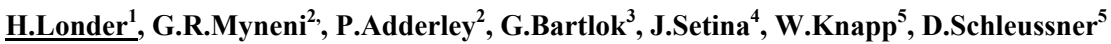 \\ Corresponding author e-mail: h.londer@konstantin-technologies.com \\ ${ }^{1}$ Product development, Konstantin Technologies, Althofen, A 9313, AUSTRIA \\ ${ }^{2}$ Jefferson lab, Newport News, Virginia 23606, USA \\ ${ }^{3}$ MAGNA STEYR Fahrzeugtechnik AG \& Co KG, Graz, A 8041, AUSTRIA \\ ${ }^{4}$ Institute of metals and technology, Ljubljana, SI 1001, SLOVENIA \\ ${ }^{5}$ Institute for Experimental Physics , Otto-von-Guericke-Universität Magdeburg, D-39106, \\ GERMANY
}

\begin{abstract}
Current "Non evaporable getters" (NEGs), based on the principle of metallic surface sorption of gas molecules, are important tools for the improving the performance of many vacuum systems. High porosity alloys or powder mixtures of $\mathrm{Zr}, \mathrm{Ti}, \mathrm{Al}, \mathrm{V}, \mathrm{Fe}$ and other metals are the base materials for this type of getters. The continuous development of vacuum technologies has created new challenges for the field of getter materials. The main sorption parameters of the current NEGs, namely, pumping speed and sorption capacity, have reached certain upper limits. Chemically active metals are the basis of a new generation of NEGs. The introduction of these new materials with high sorption capacity at room temperature is a long-awaited development. These new materials enable the new generation of NEGs to reach faster pumping speeds, significantly higher sticking rates and sorption capacities up to $10^{4}$ times higher during their lifetimes. Our development efforts focus on producing these chemically active metals with controlled insulation or protection. The main structural forms of our new getter materials are spherical powders, granules and porous multi-layers. The full pumping performance can take place at room temperature with activation temperatures ranging from room temperature to $650{ }^{\circ} \mathrm{C}$. In one of our first pilot projects, our proprietary getter solution was successfully introduced as a getter pump in a double-wall mobile $\mathrm{LH}_{2}$ tank system. Our getters were shown to have very high sorption capacity of all relevant residual gases, including $\mathrm{H}_{2}$. This new concept opens the opportunity for significant vacuum improvements, especially in the field of $\mathrm{H}_{2}$ pumping which is an important task in many different vacuum applications.
\end{abstract}

Keywords: LH2 storage system, vacuum insulation, high capacity getter.

PACS: 07.30.-t, 07.30.Cy

CP837, Hydrogen in Matter: Second International Symposium on Hydrogen in Matter (ISOHIM), edited by G. R. Myneni and B. Hjörvarsson

(C) 2006 American Institute of Physics 0-7354-0329-5/06/\$23.00 


\section{Company Information}

Konstantin Technologies is a high-tech metallurgy company specializing in processing alkali and alkaline earth metals. The project started in 1996 in an Israeli incubation center and later moved to Austria in 2001. Our main business interests are in the fields of getters and vapour sources. We are specialized in working with active metals with known gas sorbing properties but are difficult to use due to their strong reactions with ambient air. Therefore, they need to be stored and handled in a protective environment until the desired reactions should take place. We have developed different processes to handle these materials and ensure that their full performance can be activated in a controllable manner.

\section{Product Advantages}

Base on the principle of metallic surface sorption of gas molecules, the current generation of the non-evaporable getters (NEGs) are important tools used to improve the performances of many vacuum systems. High porosity alloys or powder mixtures of $\mathrm{Zr}, \mathrm{Ti}, \mathrm{Al}, \mathrm{V}, \mathrm{Fe}$ and other metals are the base materials for this type of gas sorbent getters. However, the continuous development of vacuum technologies has created new challenges for the field of getter materials since the main performance parameters of the current NEGs, namely, pumping speed and sorption capacity, have reached a certain upper limit.

Alkali and alkali earth metals are the basis of the new generation of getters. The introduction of these materials with known high gas sorption capacity at room temperature to the vacuum industries is a long-anticipated development. As some of the strongest gas sorbents known, the interest in using these active metals as getters is very high. With these metals, it is possible to achieve a faster pumping speed, a significantly higher sticking rate, and a $10^{4}$ times increase in the sorption capacity.

Our developments allow us to process these active metals with controlled insulation or protection to be used as getter solutions. The main structural forms of our new getter concepts are spherical powders, granules and porous multi-layers. The full sorption and pumping performance can take place at room temperature with activation temperature ranging from room temperature to about $650{ }^{\circ} \mathrm{C}$. Our innovations open the opportunity for significant improvements in vacuuming performances especially in the area of $\mathrm{H}_{2}$ pumping, which is an important task in many different vacuum applications. 


\section{Mobile Liquid Hydrogen Storage Project}

In one of our first pilot projects, our proprietary Tube Getter (TG) technology was implemented successfully in a mobile liquid hydrogen $\left(\mathrm{LH}_{2}\right)$ storage system. The project goal was to maintain the insulating vacuum in a double-walled hydrogen storage tank in the range of $10 \mathrm{E}-4$ mbar for 5 years. The vacuumed space is about 100 litres which also contains a multi-layer insulation (MLI) roughly 40 litres in volume. The main gases to be gettered by our TG are the entrapped ambient air in the MLI that leaks into the vacuum space over time and the $\mathrm{H}_{2}$ diffused thru the internal stainless steel walls.

The standard sintered getter materials were unsuitable for this application due to their high activation temperature which can damage the insulation and their potential to spark from impacts. Therefore, a new, alternative getter solution was needed.

\section{High Capacity NEG Material}

The unique multi-layered barium $(\mathrm{Ba})$ surface of our TG is the reason behind its great sorption performance. Using our proprietary evaporation process, we can enhance the already high sorption capacity of $\mathrm{Ba}$. The normal air has a composition of approximately $78 \%$ nitrogen, $21 \%$ oxygen, less than $1 \%$ of noble gas (mostly argon) and carbon dioxide, and trace amounts of water and other compounds like methane, hydrogen and carbon monoxide. As a getter, $\mathrm{Ba}$ reacts with these gases in an exothermal chemical reaction at room temperature.

\begin{tabular}{|l|c|}
\hline Nitrogen: & $3 \mathrm{Ba}+\mathrm{N}_{2} \rightarrow \mathrm{Ba}_{3} \mathrm{~N}_{2}$ \\
\hline Oxygen: & $\begin{array}{l}\mathrm{Ba}+1 / 2 \mathrm{O}_{2} \rightarrow \mathrm{BaO} \\
\mathrm{Ba}+\mathrm{O}_{2} \rightarrow \mathrm{BaO}_{2}\end{array}$ \\
\hline Water & $\mathrm{Ba}+\mathrm{H}_{2} \mathrm{O} \rightarrow \mathrm{Ba}(\mathrm{OH})_{2}+\mathrm{H}_{2}$ \\
\hline Hydrogen & $\mathrm{Ba}+\mathrm{H}_{2} \rightarrow \mathrm{BaH}_{2}$ \\
\hline Carbon dioxide & $\mathrm{Ba}+3 \mathrm{CO}_{2} \rightarrow 2 \mathrm{BaCO}+\mathrm{C}$ \\
\hline $\begin{array}{l}\text { Carbon } \\
\text { monoxide }\end{array}$ & $\mathrm{Ba}+\mathrm{CO} \rightarrow \mathrm{BaO}+\mathrm{C}$ \\
\hline
\end{tabular}

FIGURE 1. Reactions of Ba with ambient air components. 


\section{Tube Getter (TG) Concept}

Our basic concept is to take advantage of the strong gas sorbing property of $\mathrm{Ba}$. We have developed a special evaporation process to deposit more than 1000 layers of $\mathrm{Ba}$ which are physically, but not metallurgically, bonded to the inner surface of our TG. This process allows us to create a highly reactive getter mass with extremely large surface area. The gas inlet to this getter area in our TG is protected by a temperature sensitive sealing. With a simple heating process we were able to activate the TG to start absorbing all kind of residual gases in a vacuum system.

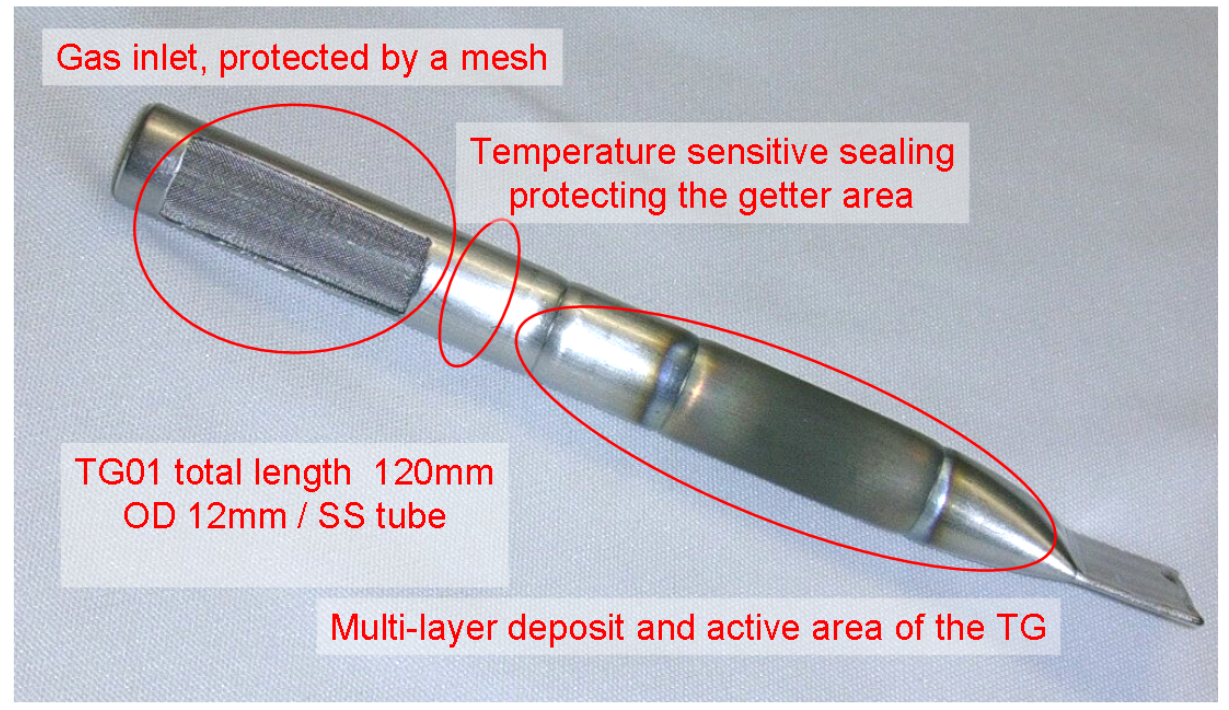

FIGURE 2. The TG concept 


\section{TG Activation}

For the $\mathrm{LH}_{2}$ storage project, the TGs were mounted on the inner side of the $\mathrm{LH}_{2}$ tank wall and were activated by heating using an industrial hot air device. The vacuum space was then sealed after the activation and cooling periods. From this moment on the TGs proceeded to pump down the total pressure a more few mbar until the internal pressure stabilized. The pressure in the vacuum space dropped further after the filling of liquid hydrogen due to the cryogenic effect which further improved its insulation property. The vacuum level of the test tank was then monitored precisely using a spinning rotor gauge. With two TG, we were able to protect the vacuum insulation in a range of 10E-4 mbar. It was projected that this protection can be maintained up to 5 years.

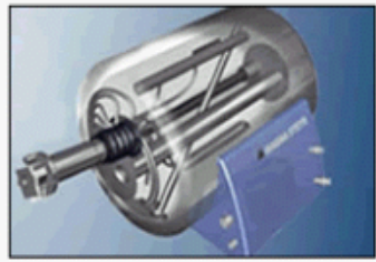

II MAGNA STEYR more value •more car

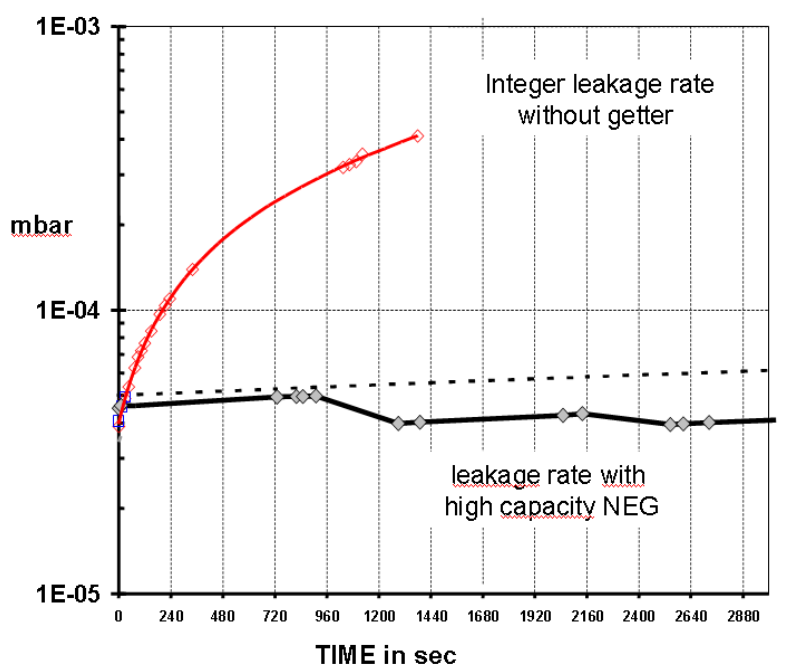

Source: Magna Steyr

FIGURE 3. $\mathrm{LH}_{2}$ tank vacuum performance 


\section{Performance Verification}

During the testing period, the ability of our TGs to reduce and maintain the total pressure level in the vacuum space and absorb as many gases in the ambient air spectrum as possible is confirmed. The performance of our multi-layered Ba getter concept was verified by reproducing the actual vacuum environment of the $\mathrm{LH}_{2}$ tank in our UHV chamber. The release of the entrapped ambient air in the MLI was simulated by introducing a small amount of ambient air using a needle valve into the UHV chamber where a TG was installed. The curves of the chamber pressure with and without the activated TG were compared and our TG was found to be able to protect the chamber vacuum down to $10 \mathrm{E}-7$ mbar for an extended period of time.

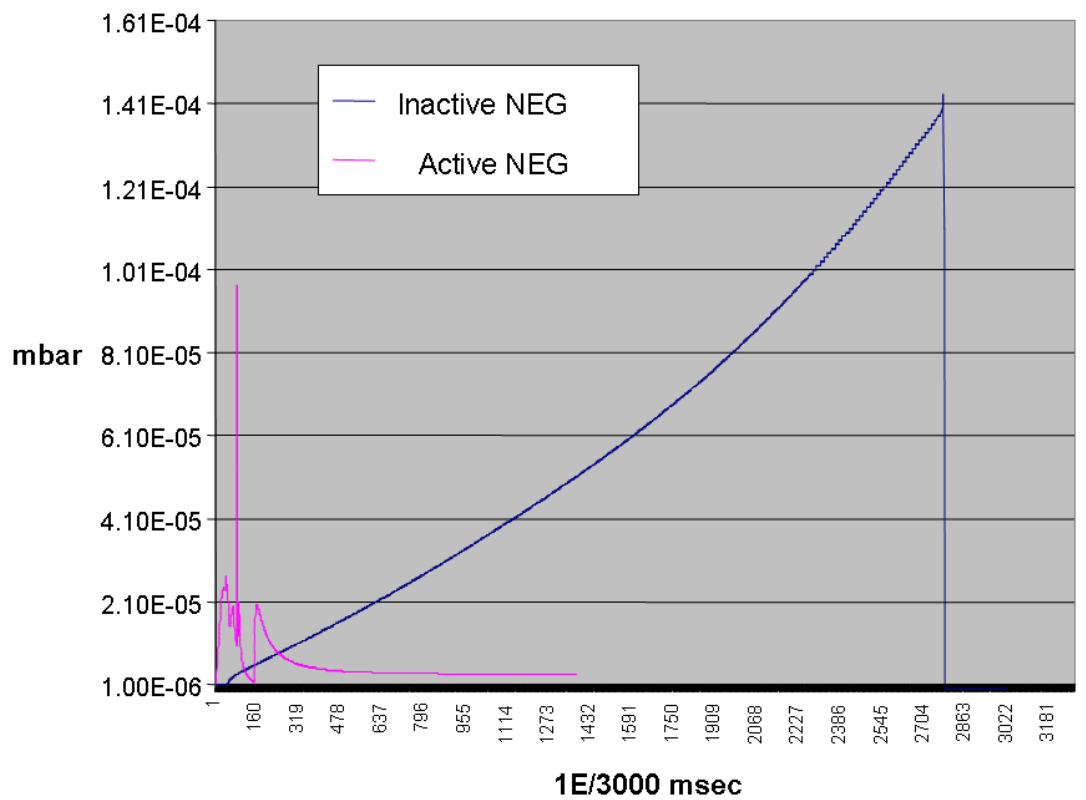

FIGURE 4. Comparison between the internal outgas rate of a $3 \mathrm{~L}$ UHV chamber with and without a activated TG (active mass: 200mg Ba) 


\section{Experimental Set-up}

In co-operation with our colleagues at the Otto von Guericke University in Magdeburg, we have also attempted to characterize the pumping speed and sorption capacity of our TG using the ASTM standard.

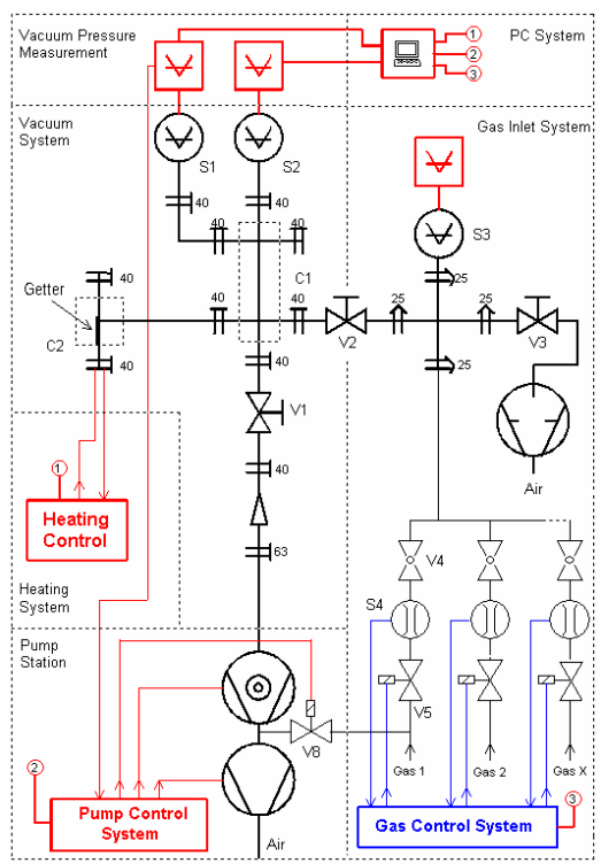

Symbols: S: Sensors for total, partial (QMS) and gas-flow measurements

V: Valves

C: Vacuum chamber

Measurement devices:

C1: Double crossing CF 40

C2: $T$ section CF 40

V1: Full metal valve CF 40 (main valve) VAT

V2: UHV-metering valve, type UDV 040 Balzers

V3: Angle valve KF 25

V4: Gas flow valve (part of S4)

Sensors:

S1: Bauert-Alpert Pirani Gauge, Type BPG 400 INFICON

S2: RGA (QMS), Type SRS RGA 100

Stanford Research System

S3: Pirani Gauge, Type TR 301

(total pressure measurement of gas inlet system / vacuum cleaning process)

Leybold

S4: Gas-flow system with gas-flow measurement, type F-200C ( $5 \mathrm{mln} / \mathrm{min})$, Bronkhorst HIGH-TEC

FIGURE 5. Test system schematic (according to ASTM standards)

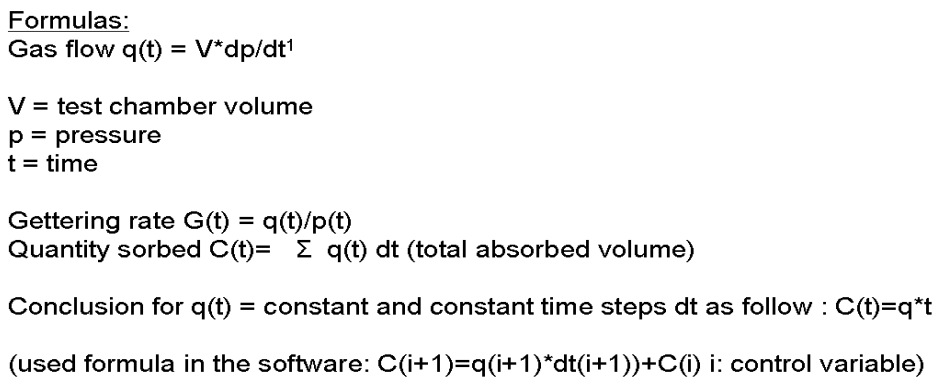

FIGURE 6. Governing equations 


\section{Test Results}

Since the performance of our TG at room temperature is about 1500 times better than the standard getter solutions, it soon became apparent that we would have to re-adjust the pressure and quantity of $\mathrm{H}_{2}$ introduced to our getter if we would to follow the procedures specified in the ASTM standard. For pumping $\mathrm{H}_{2}$, our TG's capacity is nearly that of a small turbo molecular pump with pumping speed in the area of $2 \mathrm{l} / \mathrm{sec}$. Using the sorption rate of $\mathrm{N}_{2}$ as a base line, our TG's sorption capacity for $\mathrm{H}_{2}$ is roughly 2 to 4 times higher.

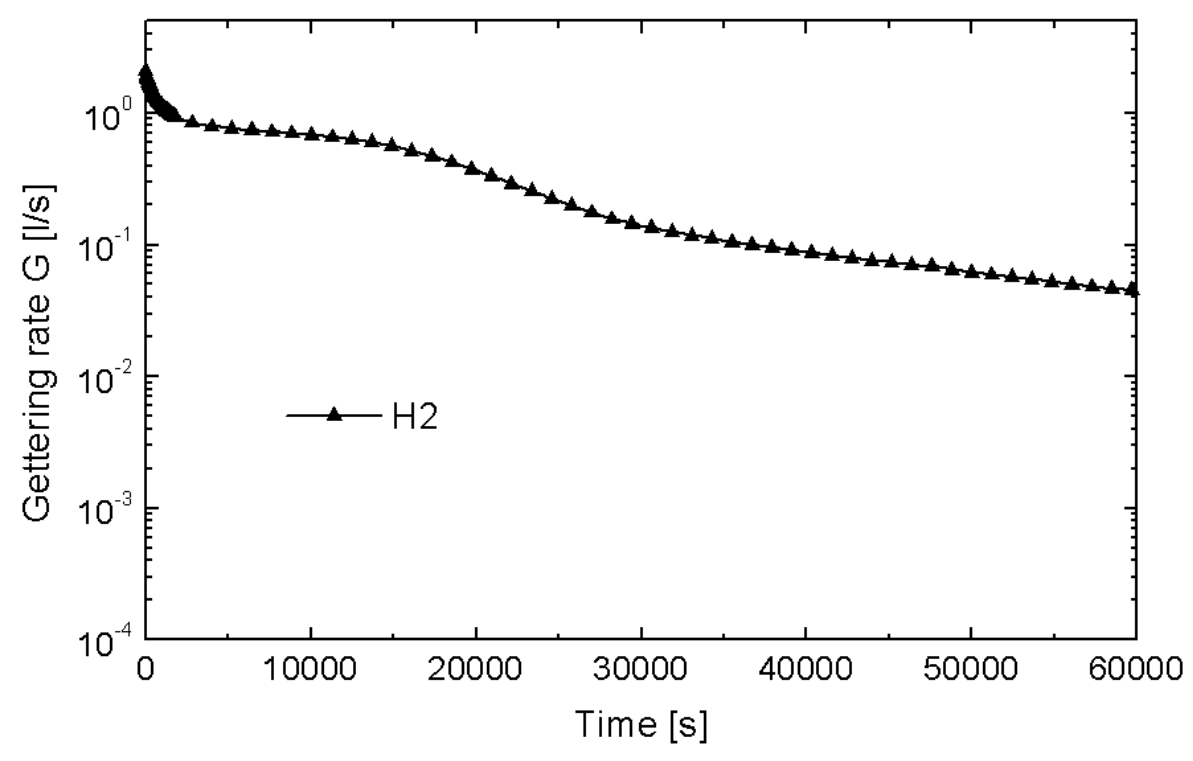

FIGURE 7. Gettering rate $\mathrm{G}[1 / \mathrm{s}]$ vs. time $[\mathrm{s}]$ for Hydrogen

With our TG gettering solution, we have greatly exceeded the current limit of sorption capacity at room temperature. It is an excellent solution for sealed and vacuumed devices which require their vacuum levels maintained in the range of $10 \mathrm{E}-5$ to $10 \mathrm{E}-6$ mbar over extended periods of time. 


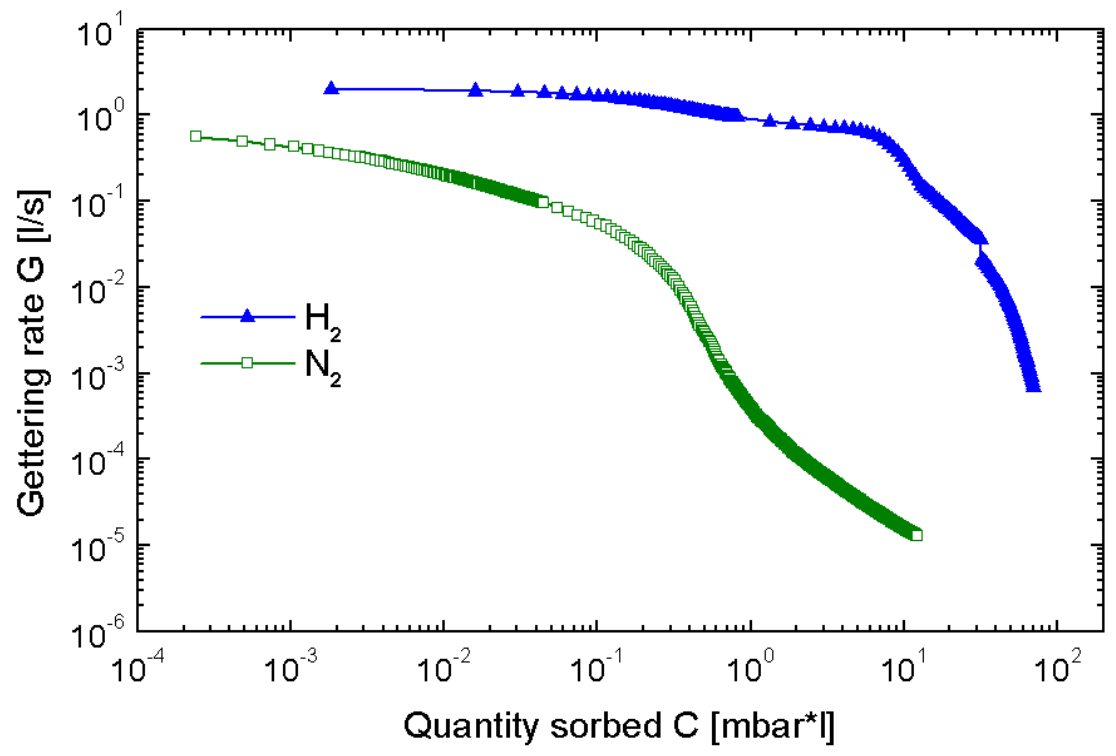

FIGURE 8. Gettering rate $\mathrm{G}[1 / \mathrm{s}]$ vs. quantity sorbed $\mathrm{C}[\mathrm{mbar} * 1]$ for $\mathrm{H}_{2}$ and $\mathrm{N}_{2}$

Gas flow

TG01-03 (H2): $\mathrm{q}=4,57^{*} 10-4 \mathrm{mbar}^{*} / \mathrm{s}$

TG01-04 (N2): $q=0,81 * 10-4 \mathrm{mbar}^{*} / \mathrm{s}$

Gettering rate $G(t)=q / p(t)$

Initial gettering rate $\mathrm{Ginit}=\mathrm{G}(\mathrm{t}=3 \mathrm{~min})$

TG01-03 $\left(\mathrm{H}_{2}\right)$ Ginit=1,69 l/s

TG01-04 $\left(\mathrm{N}_{2}\right)$ Ginit=0,17 I/s

FIGURE 9. Summary of the TG performance 


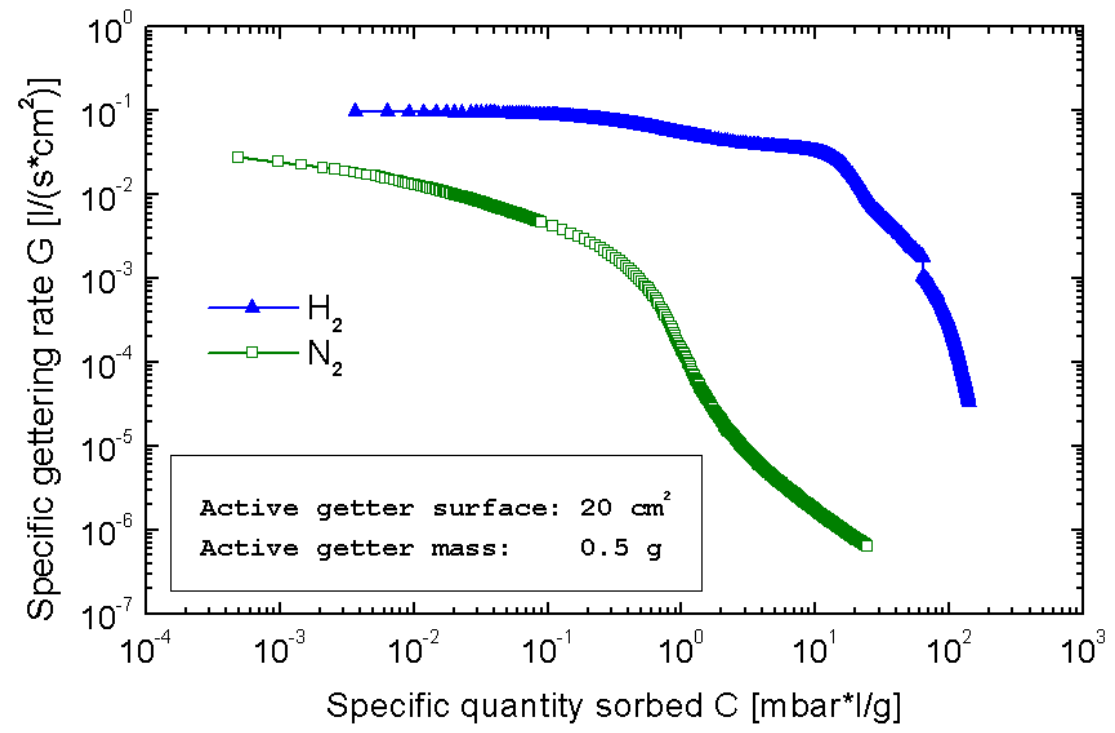

FIGURE 10. Specific gettering rate $G\left[\mathrm{~L} / \mathrm{s} \cdot \mathrm{cm}^{2}\right]$ verse specific quantity sorbed $\mathrm{C}[\mathrm{mbar} \cdot 1 / \mathrm{g}]$ for the $\mathrm{TG}$

\section{Future Development}

The TG project is now in a stage where we are finishing the process specifications and are ready to move on to a small-scale production. In addition to the TG project, we have also filed patents for several other innovations. We have developed processes to chemically passivate the surfaces of highly active getter alloys. These technologies will allow these novel materials to be used in smaller microelectronic devices. Furthermore, we have also researched in producing evaporable getter materials containing high concentration of alkali and alkali earth metals. Future researches in our company are also focusing on principle developments of sublimation pumps with repeatable pumping performance. On the material side, we are developing different alloys that will allow us to fine-tune the pumping characteristics of such sublimation pumps.

\section{Acknowledgment}

I want to thank specially our project partners in the Jefferson Lab, the University of Magdeburg, the IMT Slovenia and the Magna project team. Their supports and cooperations were essential to our developments and consequent successes in the last two years. 


\section{References}

1. R. N. Bloomer, 1957, British Journal of Applied Physics, 8, pp. 352-355

2. ASTM standard F798-97 Standard Practice for Determining Getting Rate, Sorption Capacity, and Gas Content of Nonevaporable Getters in the Molecular Flow Region, 2002 